\title{
The effect of pancreatectomy and other agents on iron absorption and storage in the rat
}

\author{
R. SINNIAH, ${ }^{1}$ T. K. BELL, AND D. W. NEILL \\ From The Department of Pathology, The Queen's University, The Medical Physics and Biochemistry Depart- \\ ments, Royal Victoria Hospital, Belfast, N. Ireland
}

SYNOPSIS Evidence from both animal and human studies had been presented by various authors to suggest that reduction of pancreatic function increased iron absorption. The present experimental studies in rats showed that there was increased radioiron $\left({ }^{59} \mathrm{Fe}\right)$ absorption after pancreatectomy, but this appeared to be due to the operative procedure as there was a similar increased absorption in animals who had sham operations performed. There was no certain evidence that pancreatic enzymes or extract had a specific inhibitory effect on the absorption of iron. But with increased doses of pancreatic extract, above the normal doses, the amount of radioiron absorption was greatly enhanced.

A significant increase in hepatic storage iron was found in the groups of rats who had been fed a diet supplemented with dl-ethionine. All these animals showed extensive damage and atrophy of the pancreas, with degeneration and considerable regenerative activity in the liver. The absolute increased hepatic storage iron was not due to the liberation and laying down of haemosiderin from the damaged cells or to decreased liver mass. Rats who had carbon tetrachloride-induced liver cirrhosis without pancreatic damage showed no increased hepatic storage iron.

It was observed that in liver damage with considerable cellular proliferation there was increased liver iron content. As this was found only when there was associated pancreatic injury, it is suggested that decreased pancreatic function in the presence of liver cell injury with cellular proliferation leads to increased iron absorption and storage. The relationship of liver injury with cellular proliferation and pancreatic damage to increased hepatic storage iron merits further study.

There is evidence from both animal (Taylor, Stiven, and Reid, 1931 and 1935; Kinney, Kaufman, and Klavins, 1955) and human studies (Davis, 1961) to suggest that reduction of pancreatic secretion increases iron absorption and encourages its deposition in the tissues. Biggs and Davis (1963) showed that the absorption of iron in patients with haemochromatosis can be reduced by the administration of a pancreatic extract. They postulated that a primary pancreatic defect may be responsible for the excess absorption and deposition of iron in patients with idiopathic haemochromatosis. However, there is an apparent discrepancy between the findings of increased absorption of iron in pancreatic disease and the lack of siderosis. Reports of siderosis in chronic pancreatitis are rare, and Gambill (quoted by Murray and Stein, 1966) was unaware of any 'Present address: Department of Pathology, University of Singapore Received for publication 17 August 1972. significant degree of it in a continuing review of 500 cases of chronic relapsing pancreatitis at the Mayo Clinic.

Simpson, Farber, and Tarver (1950) and Popper, de la Huerga, and Koch-Weser (1952) observed that dl-ethionine, a presumed antagonist to methionine, inhibited protein synthesis and induced a rapid fatty infiltration with cellular damage of the liver. A diffuse pancreatitis with destruction of the acinar glands and preservation of the islets of Langerhans also occurred with the administration of dl-ethionine (Farber and Popper, 1950). Using dl-ethionineinduced pancreatitis in rats as models, Kinney et al (1955) observed increased iron absorption and deposition in the livers of their animals. Golberg and Smith (1960) and Klavins, Kaufman, and Kinney (1962) also observed experimentally that certain cellular injuries enhanced the deposition of iron in liver parenchymal cells. 
In the present study, experiments were designed to study the effect of pancreatectomy, sham operations, and pancreatic enzymes and extract on the absorption of radioiron in rats. Hepatic storage iron was determined in rats who had dl-ethionineinduced liver and pancreatic injury. The effect of pancreatin on the degree of liver iron storage was studied in this group of animals. Hepatic storage iron was also determined in another experimental model which had carbon tetrachloride $\left(\mathrm{CCl}_{4}\right)$ induced cirrhosis without histological evidence of pancreatic damage.

\section{Material and Methods}

THE EFFECT OF PANCREATECTOMY AND SHAM OPERATIONS ON THE ABSORPTION OF RADIOI RON

Male and female Wistar albino rats weighing 220 to $250 \mathrm{~g}$ each were used in these series of experiments. Animals starved for 24 hours had the pancreas removed by a modification of the technique described by Shapiro and Pincus (quoated by Farris and Griffith, 1949) under light ether anaesthesia. After the completion of the operation, the organs were replaced in their normal positions, and the animals were kept warm and given normal saline to drink for two days following operation. Forty animals were pancreatectomized but only 26 survived $28+$ days following operation. These animals belonged to groups II and IIIb (table I). Further groups of animals had portions of omental fat and abdominal muscle excised, and these were used as 'sham-operated' controls in the study. There were eight and 10 animals respectively in these two groups (IV and V). All these animals survived the operation and there was no postoperative mortality. The operated animals had to survive a period of $28+$ days before they were used in the study. All animals were nursed in separate cages. There was no loss of weight in the control and 'sham-operated' animals, but the rats which had been pancreatectomized lost about 5 to $10 \%$ of body weight. The pancreatectomies in these animals must be incomplete because the animals lived for $28+$ days without in- sulin, and yet were not ketoacidotic. Scow (1956) has shown that total pancreatectomy in the rat induces fatal ketoacidosis in $\mathbf{4 8}$ hours.

\section{RADIOACTIVE IRON ABSORPTION STUDIES}

After fasting for 24 hours, $2 \mu \mathrm{Ci}$ of ${ }^{59} \mathrm{Fe}$ in the form of ferric chloride (supplied by the Radiochemical Centre, Amersham, Buckinghamshire), with $50 \mu \mathrm{g}$ of ferrous sulphate and $4 \mathrm{mg}$ of ascorbic acid in $1 \mathrm{ml}$ of water was delivered into the stomach of each rat through a polythene tube with the animal under light ether anaesthesia. The animals were counted immediately to determine the $100 \%$ activity value. For counting purposes the rats were placed in a ring counter with Geiger Müller tubes, and the activity was expressed as a percentage of the initial total body radioactive count. At the end of the isotope study, which was carried out for six consecutive days, the animals were killed and haemoglobin determinations and examinations of the pancreas were done. The animal cages were cleaned on alternate days, and the waste collected for radioactive disposal.

THE EFFECT OF EXOGENOUS PANCREATIC ENZYMES AND EXTRACTS ON THE ABSORPTION OF RADIOIRON

This section describes a second series of experiments designed to investigate the effect of exogenous pancreatic enzyme preparations and crude pancreatic extracts on iron absorption in intact rats. A control group of animals was included in these experiments. Ninety-one male and female Wistar albino rats weighing 220 to $250 \mathrm{~g}$ each were divided into nine groups of eight to 12 animals each, and apart from the control group I (table II), groups II, III, IV, V, and VI were given $0.05 \mathrm{~g}$ of pancreatin (Pancrex V), amylase, lipase, trypsin, and crude pancreatic extract. Groups VII, VIII, and IX were given $0 \cdot 10$ and $0.25 \mathrm{~g}$ crude pancreatic extract and $0.20 \mathrm{~g}$ pancreatin respectively. All these animals survived the study, and there was a $5-10 \%$ increase in the weights of these animals.

Crude pancreatic extract was prepared from fresh hog pancreas obtained from the Belfast abattoir.

\begin{tabular}{|c|c|c|c|c|c|c|c|}
\hline \multirow[t]{2}{*}{ Group } & \multirow[t]{2}{*}{ Experiment } & \multirow{2}{*}{$\begin{array}{l}\text { No. of } \\
\text { Rats }\end{array}$} & \multicolumn{2}{|c|}{$H b(g / 100 \mathrm{ml})$} & \multicolumn{3}{|c|}{${ }^{59} \mathrm{Fe}$ Remaining on Sixth Day (\%) } \\
\hline & & & Mean & $S D$ & Mean & $S D$ & $t$ Test on Log Results \\
\hline $\begin{array}{l}\text { I } \\
\text { II } \\
\text { IIIa } \\
\quad \text { b } \\
\text { IV } \\
\text { V }\end{array}$ & $\begin{array}{l}\text { Controls } \\
\text { Pancreatectomized } \\
\text { Prepancreatectomy } \\
\text { Postpancreatectomy } \\
\text { Sham operation (fat) } \\
\text { Sham operation (muscle) }\end{array}$ & $\begin{array}{r}16 \\
16 \\
10 \\
10 \\
8 \\
10\end{array}$ & $\begin{array}{l}14 \cdot 6 \\
12 \cdot 2 \\
15 \cdot 0 \\
12 \cdot 6 \\
13 \cdot 0 \\
13 \cdot 0\end{array}$ & $\begin{array}{l}2 \cdot 2 \\
3 \cdot 1 \\
2 \cdot 4 \\
3 \cdot 2 \\
3 \cdot 4 \\
3 \cdot 0\end{array}$ & $\begin{array}{r}6 \cdot 94 \\
15 \cdot 30 \\
7 \cdot 23 \\
16 \cdot 63 \\
23 \cdot 10 \\
18 \cdot 00\end{array}$ & $\begin{array}{r}3 \cdot 89 \\
6 \cdot 40 \\
4 \cdot 40 \\
5 \cdot 68 \\
13 \cdot 31 \\
12 \cdot 50\end{array}$ & $\begin{array}{l}P<0.001 \\
\left\{\begin{array}{l}\text { Paired } t \text { test } \\
P<0.001\end{array}\right. \\
P<0.001 \\
P<0.001\end{array}$ \\
\hline
\end{tabular}

Table I Percentage radioiron remaining on the sixth day in control animals, pancreatectomized, and sham-operated rats 


\begin{tabular}{|c|c|c|c|c|c|}
\hline \multirow[t]{2}{*}{ Group } & \multirow[t]{2}{*}{ Experiment } & \multirow[t]{2}{*}{ No. of Rats } & \multicolumn{3}{|c|}{${ }^{89} \mathrm{Fe}$ Remaining on Sixth Day (\%) } \\
\hline & & & Mean & $S D$ & $t$ Test on Log Results \\
\hline $\begin{array}{l}\text { I } \\
\text { II } \\
\text { III } \\
\text { IV } \\
\text { V } \\
\text { VI } \\
\text { VII } \\
\text { VIII } \\
\text { IX }\end{array}$ & $\begin{array}{l}\text { Control } \\
\text { Pancreatin } 0.05 \mathrm{~g} \\
\text { Amylase } 0.05 \mathrm{~g} \\
\text { Lipase } 0.05 \mathrm{~g} \\
\text { Trypsin } 0.05 \mathrm{~g} \\
\text { Crude pancreas } 0.05 \mathrm{~g} \\
\text { Crude pancreas } 0.10 \mathrm{~g} \\
\text { Crude pancreas } 0.25 \mathrm{~g} \\
\text { Pancreatin } 0.20 \mathrm{~g}\end{array}$ & $\begin{array}{r}10 \\
11 \\
12 \\
12 \\
11 \\
8 \\
9 \\
8 \\
10\end{array}$ & \begin{tabular}{r|}
$7 \cdot 9$ \\
$8 \cdot 1$ \\
$8 \cdot 9$ \\
$9 \cdot 0$ \\
$10 \cdot 7$ \\
$8 \cdot 7$ \\
$27 \cdot 0$ \\
$34 \cdot 4$ \\
$28 \cdot 9$
\end{tabular} & $\begin{array}{r}5 \cdot 1 \\
3 \cdot 0 \\
3 \cdot 5 \\
3 \cdot 8 \\
5 \cdot 3 \\
5 \cdot 0 \\
13 \cdot 4 \\
6 \cdot 8 \\
7 \cdot 5\end{array}$ & $\begin{array}{l}0.30>P>0.20 \\
0.10>P>0.05 \\
0.10>P>0.05 \\
0.20>P>0.10 \\
0.70>P>0.60 \\
0.01>P>0.001 \\
P<0.001 \\
P<0.001\end{array}$ \\
\hline
\end{tabular}

Table II Percentage of radioiron remaining on the sixth day in control animals and rats administered different pancreatic enzymes and extracts

The fresh pancreatic tissue was divided into small pieces and a fine emulsion was prepared. Pancreatin is a preparation of activated whole dried pancreas having a tryptic and lipase activity approximately equal to five times that of pancreatin BP. The amount of pancreatin used in each animal was approximately equal in tryptic and lipase activity to $0.05 \mathrm{~g}$ of pancreatin BP. The enzyme was supplied by Paines \& Byrne Ltd, Greenford, England. The amylase (diastase) was prepared by Gurr's of London; the lipase from hog pancreas by KochLight Laboratories Ltd, with an activity of 2 units per mg; and trypsin was manufactured by DIFCO Laboratories, Detroit, USA. The total body radioactivity in all the rats was measured for six consecutive days, and the sixth day absorption was calculated as in the previous studies.

EFFECT OF DL-ETHIONINE-INDUCED LIVER AND PANCREATIC INJURY ON HEPATIC STORAGE IRON IN THE RAT

Seventy-five Wistar albino rats, both male and female, weighing 220 to $250 \mathrm{~g}$ each, were used in the series of experiments in this section of the present study. The animals were divided into six dietary groups and fed ad libitum. All the 14 animals used as controls, group I (table III), survived the $28+$ days period of study. They were fed on a basal diet of calf-nuts. They showed a $10 \%$ increase in body weight on the 28th day. All nine animals used in group III and fed the basal diet with $2 \%$ supplemental ferric citrate survived and showed a $5-10 \%$ increase in body weight. Initially, in groups II, IV, V, and VI, 15, 15, 12, and 10 animals were used respectively. However, for the purpose of this study only $12,13,10$, and seven animals in the respective groups survived the $28+$ days period. All the animals in these groups showed a 20 to $25 \%$ decrease in body weight at the completion of the $28+$ days period of study. These groups of animals were fed the basal diet supplemented with $0.5 \%$ dl-ethionine or $0.5 \%$ dl-ethionine with $2 \%$ ferric citrate, and animals in groups V and VI also had $1 \%$ and $4 \%$ pancreatin added. The details of these experiments are shown in table III. All the animals were weighed at weekly intervals and killed after a four-week period on the appropriate diet. Before death, $5 \mathrm{ml}$ of blood was obtained by cardiac puncture, with the animals under ether anaesthesia. At necropsy, portions of the various organs were

\begin{tabular}{|c|c|c|c|c|c|c|c|}
\hline \multirow[t]{3}{*}{ Group ${ }^{2}$} & \multirow[t]{3}{*}{ No. of Rats } & \multicolumn{3}{|c|}{ Liver Iron Content } & \multirow{3}{*}{$\begin{array}{l}\text { Liver Weight } \\
\text { Change }(\%)\end{array}$} & \multirow{3}{*}{$\begin{array}{l}\text { Liver Iron } \\
\text { Change (\%) }\end{array}$} & \multirow{3}{*}{$\begin{array}{l}\text { Histological Liver Iron } \\
(0 \text { to }+4)\end{array}$} \\
\hline & & \multirow{2}{*}{$\begin{array}{l}\text { Total Mean } \\
(m g)\end{array}$} & \multicolumn{2}{|c|}{ mg/100g Wet Weight } & & & \\
\hline & & & Mean & $S D$ & & & \\
\hline $\begin{array}{l}\text { I } \\
\text { II } \\
\text { III }\end{array}$ & $\begin{array}{r}14 \\
12 \\
9\end{array}$ & $\begin{array}{l}0.82 \\
1.51 \\
1.07\end{array}$ & $\begin{array}{l}8 \cdot 5 \\
22 \cdot 0 \\
10 \cdot 6 \\
\text { Analys }\end{array}$ & $\begin{array}{c}2.5 \\
16.0 \\
4.0 \\
\text { variance } P<0.001\end{array}$ & $\begin{array}{l}-30 \\
+3\end{array}$ & $\begin{array}{l}+158 \\
+25\end{array}$ & $\begin{array}{c}0 \\
+2.0 \\
+0.5\end{array}$ \\
\hline $\begin{array}{l}\text { IV } \\
\text { V } \\
\text { VI }\end{array}$ & $\begin{array}{r}13 \\
10 \\
7\end{array}$ & $\begin{array}{l}5.20 \\
5.00 \\
3.00\end{array}$ & $\begin{array}{l}74 \cdot 7 \\
69 \cdot 6 \\
45 \cdot 7 \\
\text { Analys }\end{array}$ & $\begin{array}{l}20.3 \\
19.9 \\
10.9 \\
\text { variance } P>0.05\end{array}$ & $\begin{array}{l}-28 \\
-26 \\
-34\end{array}$ & $\begin{array}{l}+778 \\
+718 \\
+437\end{array}$ & $\begin{array}{l}+3.5 \\
+3.0 \\
+2.5\end{array}$ \\
\hline
\end{tabular}

\section{Table III Effect of dl-ethionine, ferric citrate, and pancreatin on liver iron deposition}

Group I, basal diet; group II, basal diet $+0.5 \%$ dl-ethionine; group III, basal diet $+2 \%$ Fe citrate; group IV, basal diet $+0.5 \%$ dl-ethionine $+2 \%$ Fe citrate; group V, basal diet $+0.5 \%$ dl-ethionine $+2 \%$ Fe citrate $+1 \%$.pancreatin; group VI, basal diet $+0.5 \%$ dl-ethionine + $2 \%$ Fe citrate $+4 \%$ pancreatin. 
fixed in formalin for histological examination. They were stained with haematoxylin and eosin ( $\mathrm{H} \& \mathrm{E})$ and with Perls' Prussian blue stain for haemosiderin. The livers were weighed immediately after the animals were killed. The livers, except for the slices removed for histological examination, were perfused with $\mathrm{N}$ saline to remove the blood from the vessels and sinusoids. The liver was dried of excess moisture and weighed. The liver non-haem iron was estimated by a modification of the method described by Kitzes, Elvehjem, and Schuette (1944).

THE EFFECT OF CCL $_{4}$-INDUCED LIVER INJURY ON HEPATIC STORAGE IRON IN THE RAT Male Wistar rats weighing 220 to $250 \mathrm{~g}$ each were used in this experiment. Eight control animals were fed on an ordinary calf-nut diet, while eight other rats were given calculated doses of $\mathrm{CCl}_{4} 1 \mathrm{ml}$ per kg of body weight once every three days. The drug was introduced through an oral tube and 10 doses were administered over a period of 30 days. These $\mathrm{CCl}_{4}$-treated rats were fed on the basal diet. After 30 days, the animals were killed and the haemoglobin, serum iron, and liver iron contents were determined. Sections from the various organs were stained with $\mathbf{H} \& \mathrm{E}$ and Perls' reaction for iron. The animals in both groups showed a $10 \%$ increase in body weight, and there were no fatalities.

\section{Results}

EFFECT OF PANCREATECTOMY AND SHAM OPERATIONS ON IRON ABSORPTION

Figure 1 illustrates the mean value of total body radioactivity in the five groups of animals used in this part of the investigation during the six consecutive days following administration of radioiron. Table I shows the percentage of ${ }^{59} \mathrm{Fe}$ remaining in the rats on the sixth day. Sixteen animals which survived pancreatectomy for four weeks (group II) showed increased radioiron absorption when compared with the control animals (group I). A Student's $t$ test showed this increase to be significant $(P<0 \cdot 001)$. Animals in group III acted as their own controls. The radioiron absorption before pancreatectomy (group IIIa) was $7 \cdot 23 \pm 4 \cdot 40 \%$, and $16.63 \pm 5 \cdot 68 \%$ four weeks after pancreatectomy (group IIIb). A paired $t$ test showed this increased absorption to be significant $(P<0.001)$. Animals which had sham operations performed-removal of omental fat in group IV and abdominal muscle in group V-also showed significant increase in radioiron absorption compared with the control animals. The haemoglobin values were decreased in the operated groups of animals. It was observed that there was increased absorption of iron in the operated animals and this

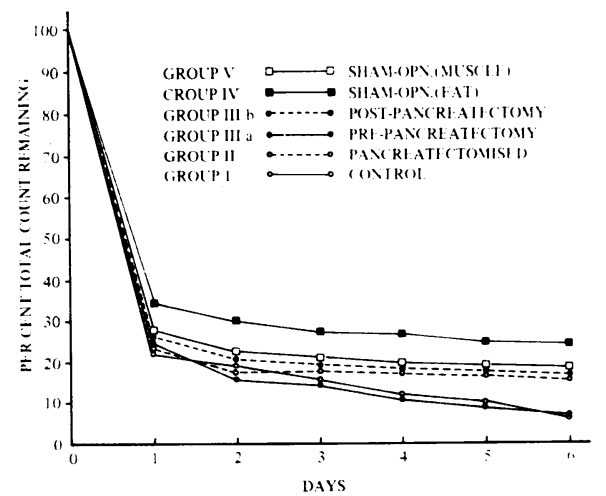

Fig. 1 Graph showing percentage of radioactivity remaining in the rats for six consecutive days. Each point represents the mean value of radioiron remaining in the group of rats.

increase was not specific to the removal of the pancreas.

EFFECT OF EXOGENOUS PANCREATIC ENZYMES AND EXTRACT ON THE ABSORPTION OF RADIOIRON

In these experiments (table II), there were nine groups of animals, group I acting as a control, while groups II, III, IV, V, and VI were given $0.05 \mathrm{~g}$ of pancreatin, amylase, lipase, trypsin, and crude pancreatic extract respectively. A Student's $t$ test showed no significant change in the amount of radioiron absorption in these animals given exogenous pancreatic enzymes and crude extract from the control animals. Animals in groups VII, VIII, and IX were given 0.10 and $0.25 \mathrm{~g}$ of crude pancreatic extract and $0.20 \mathrm{~g}$ of pancreatin respectively. In these groups of animals it was found that there was a significant increase in the amount of radioiron absorbed after the administration of increased doses of exogenous pancreatic enzymes and extracts compared with the control group of animals. Detailed results with these experiments are shown in table II.

EFFECT OF DL-ETHIONINE-INDUCED LIVER AND PANCREATICINJURY ON HEPATICSTORAGE IRON IN THE RAT

\section{Histological changes in pancreas and liver}

Rats fed a diet containing $0.5 \%$ dl-ethionine for four weeks showed severe pancreatic damage, especially of the acinar portion of the pancreas, which was markedly atrophic. In the most advanced lesions, only about $5-10 \%$ of the acinar tissue survived. The islets of Langerhans were scattered in 
the atrophic acinar tissue (fig. 2), and no histological alterations were seen in them. There was diffuse infiltration of the parenchyma by lymphocytes, monocytes, and plasma cells. The pancreas also showed marked adipose infiltration. In some areas of the pancreatic glands, the parenchyma was a skeleton of branching ducts with occasional acinar cells and supported by adipose tissue. These pancreatic changes were seen in groups II, IV, V, and VI (table III). The rats in these groups which had had dl-ethionine in their diets, showed degeneration and necrosis, as well as regeneration of hepatic cells and bile ducts, with fibroblastic proliferation in the liver parenchyma (fig. 3). There was also lymphocytic and polymorphonuclear leucocytic infiltration in the damaged areas. Fatty infiltration of the liver was seen only rarely in these animals which had been on the diet for four weeks.

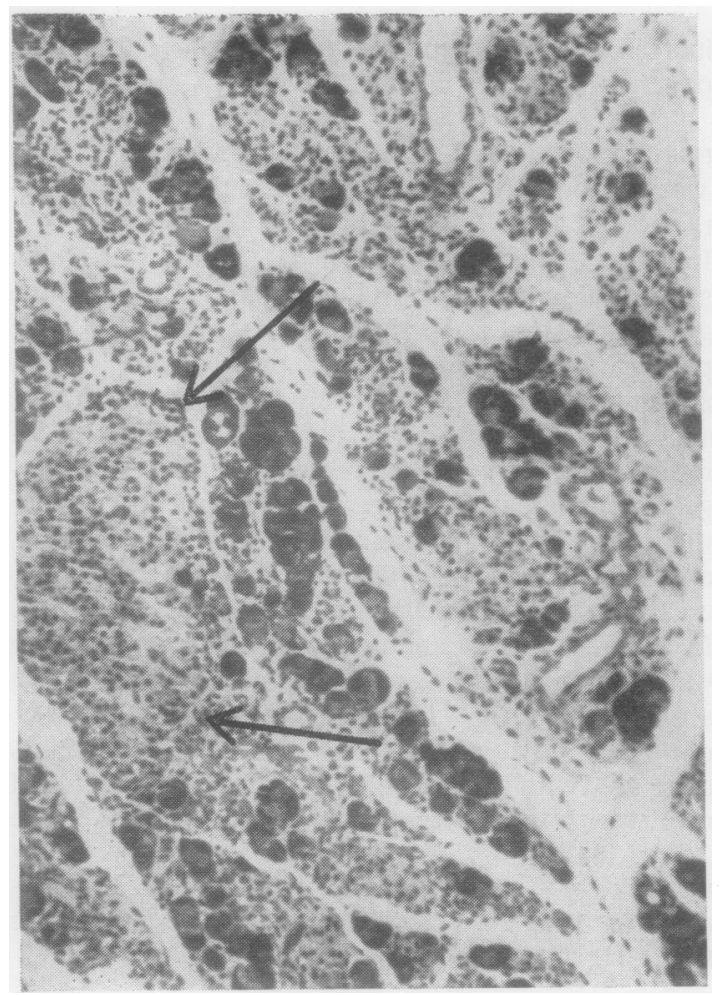

Fig. 2

\section{Deposition of iron in the liver}

Rat livers were stained for haemosiderin by Perls's method and were then graded according to the degree of severity into grades $0-4$, representing increasing amounts of stainable iron. These gradings were done with light microscopy. There was no histological evidence of iron in the livers of the control rats fed a basal diet only (group I-table III). In those animals with liver and pancreatic damage caused by dl-ethionine in their diets, there was an increased amount of stainable liver iron, which was greater than in the group of animals fed a basal diet with supplemental iron. The increased hepatic storage iron was not due to decreased liver mass as there was an absolute rise in total iron content. The increase in liver iron content was far greater than the decreased liver mass. This increased liver iron content in the animals with ethionine-

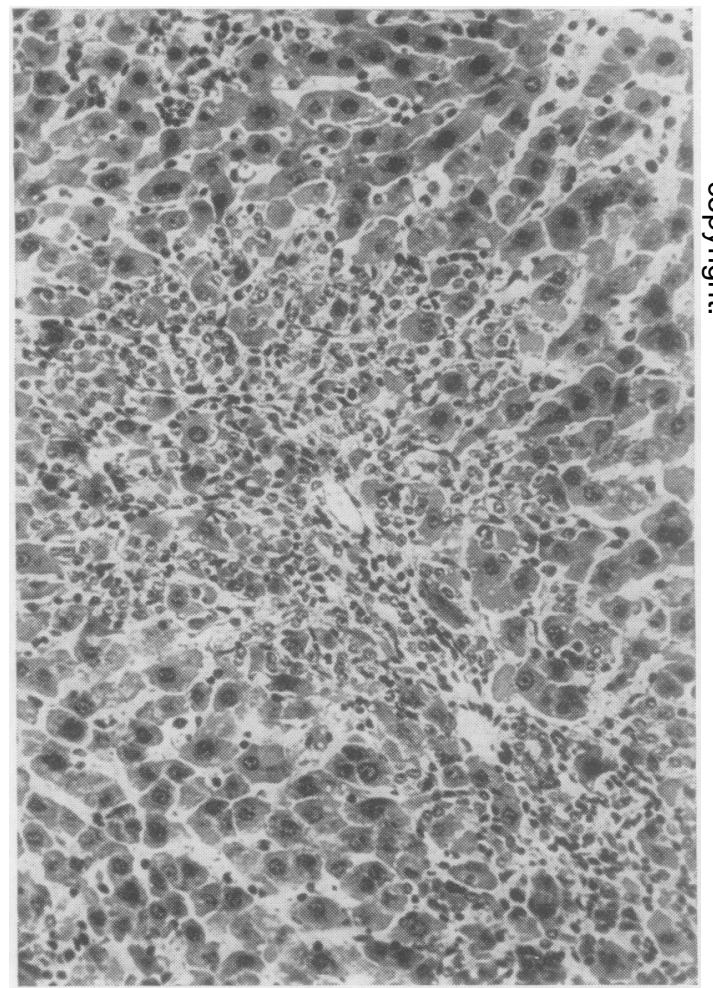

Fig. 3

Fig. 2 Rat pancreas after animal had been on a diet containing $0.5 \%$ dl-ethionine for four weeks. There is marked atrophy of acinar glands, but the islets of Langerhans (marked by arrows) are not affected. There is a diffuse infiltration of the parenchyma by lymphocytes and monocytes $(H \& E \times 160)$.

Fig. 3 Rat liver after animal had been on a diet supplemented with $0.5 \%$ dl-ethionine for four weeks. There is degeneration and necrosis of liver cells, as well as regeneration, with bile duct and fibroblastic proliferation. There is a moderate lymphocytic infiltrate $(H \& E \times 160)$. 
induced liver and pancreatic damage was significantly greater than in the control groups of animals $(P<0.001)$. With the addition of 1 and $4 \%$ pancreatin to the diet of the animals with ethionineinduced liver and pancreatic injury (groups $\mathrm{V}$ and VI-table III), there appeared to be a decrease in the liver iron content, but this was not statistically significant (analysis of variance $P>0.05$ ). It was seen that ethionine-induced liver and pancreaticinjury was associated with increased liver iron concentration, an effect that was enhanced by dietary iron supplementation. Dietary iron supplementation did not significantly increase liver iron concentration in control animals. The red cell compartment iron was excluded as all the livers were perfused with $\mathrm{N}$ saline before the liver iron contents were determined.
EFFECT OF CCL -INDUCED LIVER INJURY ON HEPATIC STORAGE IRON IN THE RAT

Histological changes in liver and pancreas

The control animals showed a normal hepatic architecture, and the parenchymal cells contained noiron on Perls's haemosiderin staining. The pancreas and other organs showed no pathological changes. After 10 doses of $\mathrm{CCl}_{4}$ given over a period of $\mathbf{3 0}$ days, there was a moderate to marked degree of fatty change, with fibrosis of the liver parenchyma (fig. 4). The fibrous septa intersected the liver parenchyma to show the features of a monolobular cirrhosis. There was mild bile duct proliferation, with a moderate degree of lymphocytic and monocytic infiltration. The pancreas (fig. 5) and other

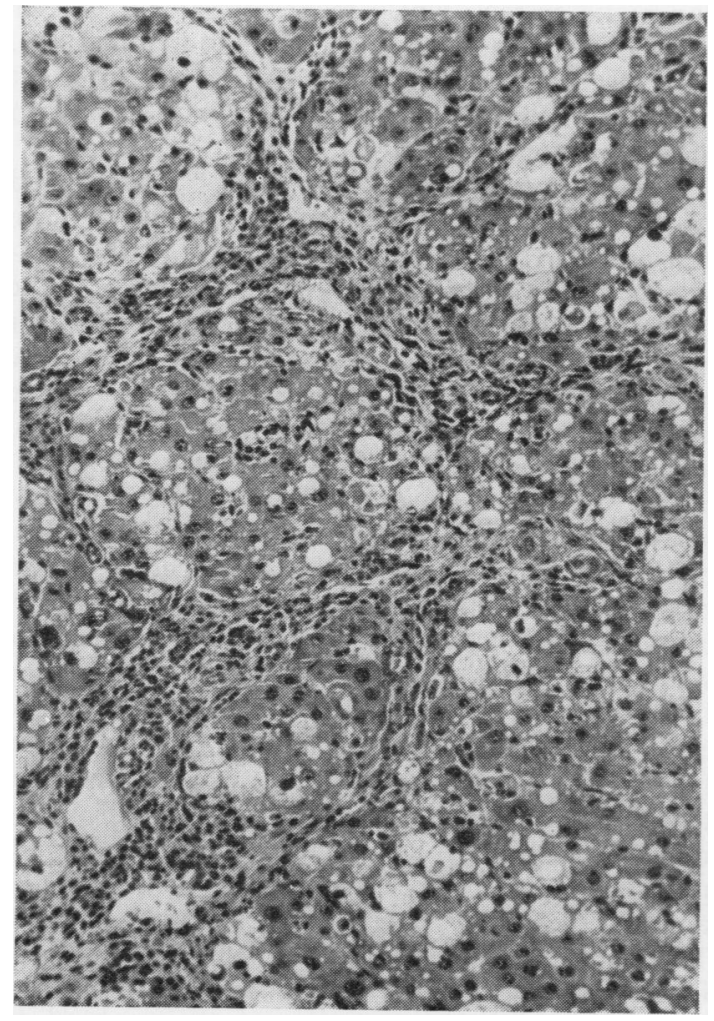

Fig. 4

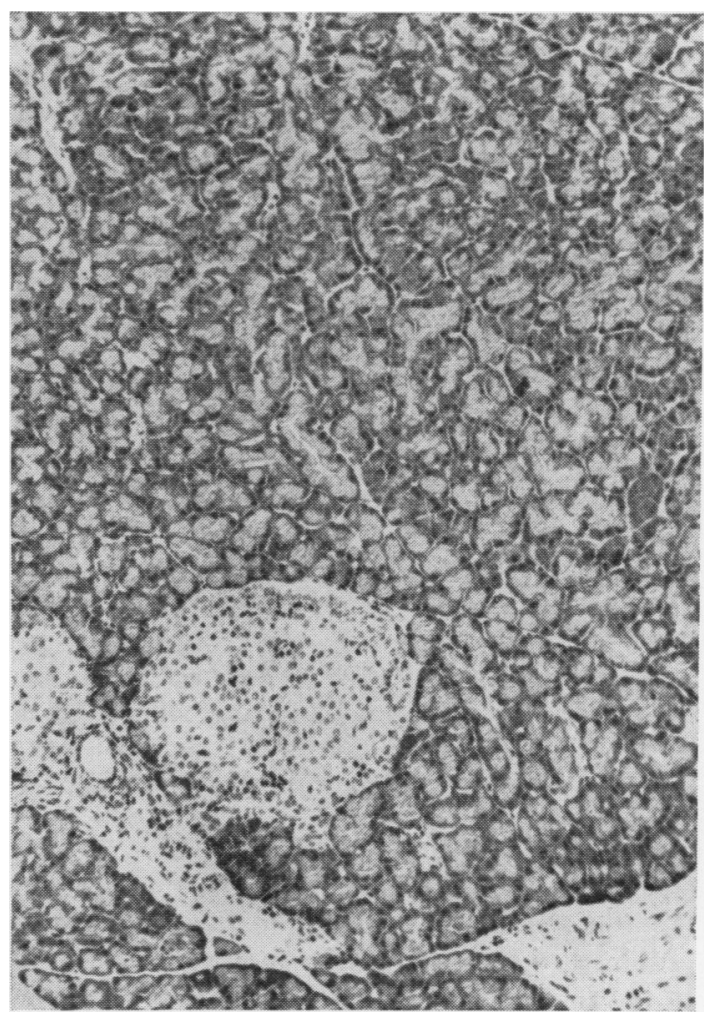

Fig. 5

Fig. 4 Rat liver. After 10 doses of carbon tetrachloride over 30 days, there is advanced hepatic fibrosis with a monolobular type of cirrhosis. The fibrous septa are well formed with proliferating fibroblasts and abundant fibre formation. There is a moderate degree of fatty change and lymphocytic infiltration $(H \& E \times 160)$.

Fig. 5 Rat pancreas. After 10 doses of $\mathrm{CCl}_{4}$ over 30 days, the pancreas does not show any significant changes $(H \& E \times 160)$. 
organs showed no evidence of histological damage, unlike the marked changes seen in dl-ethioninetreated rats.

\section{Deposition of iron in the liver}

The control animals showed no stainable iron by Perls's method, while the $\mathrm{CCl}_{4}$-treated animals had grade +1 iron. On chemical analysis, the liver iron content in the control rats was $7.85 \pm 4.06 \mathrm{mg} / 100 \mathrm{~g}$ wet weight liver, and in the $\mathrm{CCl}_{4}$-treated animals with liver cirrhosis $8.58 \pm 1.41 \mathrm{mg} / 100 \mathrm{~g}$ wet weight liver. There was no significant change in the liver iron content between these two groups of animals $(0.70>P>0.60)$. As in the previous experiments, all the livers were perfused with $\mathrm{N}$ saline before the liver iron contents were determined to exclude the red-cell-compartment iron.

\section{Discussion}

Taylor et al (1931) observed that after pancreatectomy in cats, large quantities of iron were present in the livers. They then ligated the pancreatic ducts of cats (1935) and concluded that iron was absorbed in large quantities because of damage to the epithelium of the duodenum, which they attributed to lack of vitamin A. However, Kinney, Finch, Kaufman, Hegsted, and Partington (1950) observed that iron was absorbed more readily in dogs when the pancreatic ducts were ligated, with an intact duodenal mucosa.

The studies of Davis (1961), Callender and Malpas (1963), and other workers suggested that decreased pancreatic function led to increased iron absorption and storage. Murray, Delaney, and Stein (1964) used the isolated subcutaneous jejunal loop of the dog with external counting over the loop. They could find no inhibition of the uptake of iron ${ }^{59} \mathrm{Fe}$, either with pancreatic juice from other dogs or by pancreatic extract (Viokase). They could find no binding of ${ }^{59} \mathrm{Fe}$ by water-soluble extracts of Viokase. In 1967 Murray and Stein could not demonstrate that pancreatic duct ligation led to increased absorption of ${ }^{59} \mathrm{Fe}$.

The studies reported in this paper showed increased radioiron absorption after pancreatectomy, but this appeared to be due to the operative procedure as there was a similar increased absorption in the rats which had sham operations performed. The increased radioiron absorption may be explained by a decreased total body iron due to blood loss and removal of tissue. To make good this loss, there was increased iron absorption, and the role of the pancreas appeared doubtful in regulating iron uptake from the gastrointestinal tract. Most of the published experimental studies had been un- physiological in that the animals had been subjected to exterisive surgical procedures. In the present paper, the rats in the experiments tabulated in table II were not subjected to surgical trauma, and the radioiron with the pancreatic enzymes was administered by gastric intubation with a polythene tube. There was no significant change or decrease in the radioiron absorption with the administration of $0.05 \mathrm{~g}$ pancreatic enzymes or extract. However, when the concentration of crude pancreatic extract was increased to $0 \cdot 10$ and $0.25 \mathrm{~g}$ and the pancreatin to $0.20 \mathrm{~g}$, there was a significant increase in radioiron absorption from the control group of animals (table II). We could not demonstrate any inhibitory effect on radioiron absorption by pancreatic extract or enzymes. But with increased doses of pancreatic extract, above the usual doses, the amount of radioiron absorption was greatly enhanced. This may be due to changes in the intestinal milieu and an increase in amino acids derived from the crushed pancreatic extract, which make available a greater number of chelating sites for binding luminal iron. Thus, there appeared to be no certain evidence that pancreatic extract had a specific inhibitory effect on the absorption of iron.

In the present study, the animals administere 8 dl-ethionine (table III) showed extensive damage and atrophy of the pancreas. There was also conê siderable necrosis and regenerative activity in the liver. Dl-ethionine also caused damage to other intracellular processes, eg, small bowel. The ethionine-induced liver and pancreatic injuries were associated with increased liver iron concentration, an effect that was enhanced by dietary iron supplementation. Dietary iron supplementation did not significantly increase liver iron concentration in control animals. Though there was decreased liver mass in the ethionine-treated animals; there was an absolute rise in total iron content. This increase was far in excess proportionately to the decreased liver mass. As the red cell compartment iron was excluded it is suggested that the absolute increase in liver iron content must be due to increased absorption and storage, though no absorption studies were done in these series of experiments. With the administration of $4 \%$ pancreatin to ethionine-treated animals there was a decrease in liver iron content. N There was a tendency (not statistically significant) for pancreatin administration to lessen iron ac- 0 cumulation, but the meaning of this is hard to evaluate.

In animals with $\mathrm{CCl}_{4}$-induced liver injury without $\stackrel{\oplus}{\longrightarrow}$ any histological evidence of pancreatic damage, the 0 liver iron concentration was not increased. It was $\stackrel{0}{P}$ seen that with ethionine-induced liver and pancreatic damage there was an absolute increase in 
the liver iron content, which was not found with $\mathrm{CCl}_{4}$-induced liver injury alone. It is difficult to explain the finding of increased liver iron content in the animals with ethionine-induced liver and pancreatic injury. Mendel (1964) measured iron absorption in the mouse during the period of rapid liver regeneration that follows partial hepatectomy, and found it to be strikingly and transiently increased. This increase in iron absorption was not related to the reduction in hepatic iron stores produced by the hepatectomy. These results suggested that the increase in iron absorption seen after partial hepatectomy was related to the resulting cellular proliferation. Iron absorption was increased in idiopathic haemochromatosis (Sinniah and Bell, 1968), hepatic cirrhosis (Conrad, Berman, and Crosby, 1962), and in rats with experimentally produced fatty liver (Murray and Stein, 1967). Liver regeneration is a prominent feature of idiopathic haemochromatosis, Laennec's cirrhosis, and in the livers of ethionine-treated animals (present study). It is suggestive that the increased iron absorption and liver storage iron seen in these conditions may be related to the cellular proliferation. However, in the rats with $\mathrm{CCl}_{4}$-induced liver cirrhosis, where there was evidence of a fatty change with cellular proliferation, there was no increase in the liver iron content. The explanation therefore may be more complex than mere cellular proliferation.

There was a high degree of associated pancreatic fibrosis with liver cirrhosis (MacDonald and Mallory, 1960) and idiopathic haemochromatosis. There was increased iron absorption and liver storage iron in these conditions, and in rats with ethionine-induced liver and pancreatic damage as demonstrated in the present study. It is suggested that the increased liver iron content in these states may be due to the cellular proliferation, but this can occur only when there is concomitant pancreatic injury with dysfunction. This explanation is supported by the present study with $\mathrm{CCl}_{4}$-induced liver cirrhosis with regenerative activity in rats without any demonstrable pancreatic injury. These animals showed no increased liver iron content compared with the controls. The relationship of liver injury with cellular proliferation and pancreatic damage to increased liver iron content needs further study.
We wish to thank Professor Sir John H. Biggart, CBE, for his guidance and interest in this work; Mr D. Mehaffey for the photographs, and Miss V. Tan for typing the manuscript.

\section{References}

Biggs, J. C., and Davis, A. E. (1963). Relationship of diminished pancreatic secretion to haemochromatosis. Lancet, $2,814$.

Callender, S. T., and Malpas, J. S. (1963). Absorption of iron in cirrhosis of liver. Brit. med. J., 2, 1516-1518.

Conrad, M. E., Jr., Berman, A., and Crosby, W. H. (1962). Iron kinetics in Laennec's cirrhosis. Gastroenterology, 43, 385-390.

Davis, A. E. (1961). The relationship of disturbed pancreatic function to haemosiderosis. Lancet, 2, 749-750.

Farber, E., and Popper, H. (1950). Production of acute pancreatitis with ethionine and its prevention by methionine. Proc. Soc. exp. Biol. (N.Y.), 74, 838-840.

Farris, E. J., and Griffith, J. Q. Jr., (1949). The Rat in Laboratory Investigation, 2nd ed. Lippincott, Philadelphia.

Golberg, L., and Smith, J. P. (1960). Iron overloading and hepatic vulnerability. Amer. J. Path., 36, 125-149.

Kinney, T. D., Finch, C. A., Kaufman, N., Hegsted, M., and Partington, P. F. (1950). The relation of the pancreas to the absorption of iron. Amer. J. Path., 26, 746-747.

Kinney, T. D., Kaufman, N., and Klavins, J. (1955). Effect of ethionine-induced pancreatic damage on iron absorption. J. exp. med., 102, 151-156.

Kitzes, G., Elvehjem, C. A., and Schuette, H. A. (1944). The determination of blood plasma iron. J. biol. Chem., 155, 653-660.

Klavins, J. V., Kaufman, N., and Kinney, T. D. (1962). Increased hepatic affinity for iron during ethionine administration. Fed. Proc., 21, 306.

MacDonald, R. A., and Mallory, G. K. (1960). Hemochromatosis and hemosiderosis: Study of 211 autopsied cases. A.M.A. Arch. intern. med., 105, 686-700.

Mendel, G. A. (1964). Increased iron absorption during liver regeneration induced by partial hepatectomy. J. Amer. med. Ass., 189, 369-370.

Murray, M. J., Delaney, J. P., and Stein, N. (1964). Use of isolated subcutaneous intestinal loops for direct study of intestinal absorption radioisotopes in dogs. Amer. J. dig. Dis., 9, 684-689.

Murray, M. J., and Stein, N. (1966). Does the pancreas influence iron absorption? A critical review of information to date. Gastroenterology, 51, 694-700.

Murray, M. J., and Stein, N. (1967). The effect of ligation of the pancreatic duct on the absorption of radioiron by rats. Gastroenterology, 53, 38-41.

Popper, H., de la Huerga, J., and Koch-Weser, D. (1952). Hepatic and pancreatic changes produced in rats by ethionine and their. relation to human lesions. Amer. J. Path. (Scientific Proceedings), $28,518$.

Simpson, M. V., Farber, E., and Tarver, H. (1950). Studies on ethionine. I. Inhibition of protein synthesis in intact animals. $J$, biol Chem, 182, 81-89.

Scow, R. O. (1956). 'Total' pancreatectomy in the rat: operation, effects, and postoperative care. Endocrinology, 60, 359-367.

Sinniah, R., and Bell, T. K. (1968). Radioiron absorption and utilization in idiopathic haemochromatosis using a marker. Metabolism, 17, 885-892.

Taylor, J., Stiven, D., and Reid, E. W. (1931). Haemochromatosis in a depancreatized cat. J. Path. Bact., 34, 793-797.

Taylor, J., Stiven, D., and Reid, E. W. (1935). Experimental and idiopathic siderosis in cats. J. Path. Bact., 41, 397-405. 